\title{
Increasing wind power penetration into the existing Serbian energy system
}

\author{
Ilija Batas Bjelićc ${ }^{\mathrm{a}, *}$, Nikola Rajakovića ${ }^{\text {, Boris } \text { Ćosić }^{\mathrm{b}} \text {, Neven Duić }}{ }^{\mathrm{b}}$ \\ a School of Electrical Engineering, University of Belgrade, Bulevar kralja Aleksandra 73, 11120 Belgrade, Serbia \\ ${ }^{\mathrm{b}}$ Faculty of Mechanical Engineering and Naval Architecture, University of Zagreb, Ivana Lučića 5, 10002 Zagreb, Croatia
}

\section{A R T I C L E I N F O}

\section{Article history:}

Received 31 August 2012

Received in revised form

19 March 2013

Accepted 21 March 2013

Available online 26 April 2013

\section{Keywords:}

Energy system analysis

Wind integration

Moderation costs

Smart energy systems

Demand response

\begin{abstract}
A B S T R A C T
Serbia has wind with a good capacity factor, the respectable potential of which has not hitherto been utilized. There are a number of proposed wind power projects with an envisaged capacity of up to $2500 \mathrm{MW}$ and the project documentation has been developed for $1300 \mathrm{MW}$. Within the existing feed-in tariff scheme, only $500 \mathrm{MW}$ are eligible. This limitation is set in a conservative manner bearing in mind moderation (balancing) needs due to the variability of wind power generation. The existing Serbian energy system, with significant hydro generation, available pumped storage hydro capacity, and strong interconnections has many moderators for variable wind generation and for reliable technical performance of the grid. In this study, energy imbalances under different levels of wind penetration into the Serbian energy system were analyzed. Possible new moderation strategies for lowering energy imbalances due to wind integration were evaluated using the EnergyPLAN tool and are presented in this paper.

(C) 2013 Elsevier Ltd. All rights reserved.
\end{abstract}

\section{Introduction}

The energy policy in Serbia in following years will be in between lignite and renewable energy sources (RESs). Traditionally, lignite has been used in the Serbian electrical energy system to meet the base load demand, dominantly due to low fuel costs, while hydro has been used for variable load serving. By taking into account all costs of energy generation from lignite, the overall energy picture in Serbia will be changed. It is expected that investment costs of lignite power plants will increase by $30-50 \%$ with the introduction of carbon capture and storage (CCS) technology and by $23 \%$, with increased fuel demand and therefore increased fuel costs to produce the same amount of electricity making CCS technology an unsuitable way to decrease $\mathrm{CO}_{2}$ emissions in the long term [1]. Fossil fuel subsidies in Serbia, including indirect support and net effects of cross-subsidies (e.g., tolerated non-payment by energyintensive companies) and with no environmental impact costs included, are estimated at $9 \%$ of the Serbian gross domestic product (GDP) [2]. Furthermore, with an assumed cost of $10 € / \mathrm{t}$ (or higher) for $\mathrm{CO}_{2}$ and by employment of the emission trading scheme (ETS), the costs of electricity produced from lignite will increase.

The EU accession process creates goals [3] for a new Serbian energy policy: increasing the share of renewable energy in the final

\footnotetext{
* Corresponding author. Tel.: +381 11321 8360; fax: +381 113248681.

E-mail addresses: batas@etf.rs, ilija.batas@gmail.com (I. Batas Bjelić).
}

energy consumption, mitigation of greenhouse gasses emissions referenced to the year 2009, and increasing energy efficiency. The new energy policy has to ascertain what the optimal share of renewable energy sources for Serbia [4] is and how to add more renewable energy units with the lowest additional costs. This new energy mix will be shaped by feed-in tariffs [5] and supported with the new Energy Law [6]. Wind, solar, hydro, geothermal and biomass are key renewable energy sources to reduce $\mathrm{CO}_{2}$ emissions, as well to enhance energy independence. The Serbian power system consists of large hydro units that have been used for moderation (balancing) of variable consumption for years. The good wind potential in southeast Banat [7] has provoked many studies for wind applications but new wind units would cause greater variability in energy generation and more moderation requirements for the transmission system operator (TSO).

With the new Energy Law, the Serbian TSO is obliged to moderate the energy system [8] in an economic manner [9], by paying minimal moderation costs to providers of ancillary services. An ancillary service that illustrates the hourly needs for energy moderation is called energy imbalance [10-13]. Critical excess electricity production (CEEP) [14] is the sum of energy imbalances for the whole year. In a broader sense, energy imbalance moderators [15] are:

1) Consumer load flexibility [16-19],

2) Increased flexibility from traditional generators [20-23]: 


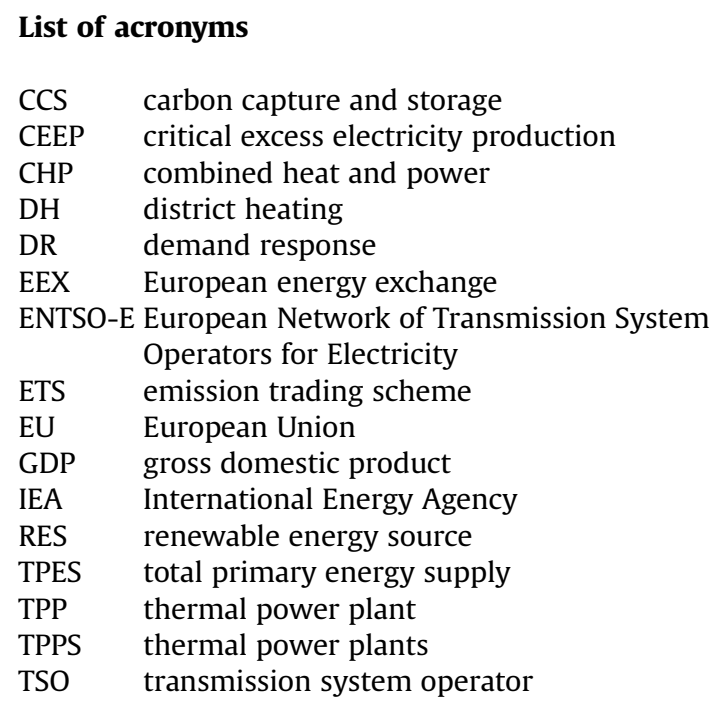

a) Reduced technical minimum,

b) On/off cycling time reductions,

c) Up/down load ramp increase,

3) Energy storage [24-27],

4) Regional market dispatch - interconnection imbalance [11,28],

5) Transmission upgrades [26,27],

6 ) The integration of the different sectors in the energy system which are electricity, heat, and transport [24]

7) Curtailment of wind production [16,26].

Regional market dispatch and transmission upgrades are external moderators. When the TSO operates as a closed balancing area, without external moderators, that mode of operation is called an island mode while, it is called a connected island mode when using external moderators. From the view of energy system planners, in order to moderate increased variability, it is better to increase the flexibility in their own system and optimize moderation costs within the island mode, rather than export energy in a forced manner with an unpredictable market price within the connected island mode [9]. Since curtailment of wind power is not a favourable option when the share of renewable energy and $\mathrm{CO}_{2}$ mitigation goals are to be met, the existing generation units and existing load should under these circumstances operate with increased flexibility. In the existing Serbian energy system, without investment in new generation, storage or transmission capacities, increased flexibility in the generation and on the demand side are the first moderators to be evaluated within the island mode. Increasing the flexibility of thermal power plants (TPPS) would result in fuel savings during variable wind generation. When wind is dispatched as a must-run unit up to the envisaged potential and all existing generation units are at maximum flexibility, then external moderators have to be evaluated in the connected island mode.

Increased consumer load flexibility with demand response (DR) options were presented in a two-step technical and economic optimization in order to determine the optimal share of energy imbalance moderators: storage and upgrade of transmission interconnection [26], while minimizing wind curtailment in the case of large-scale integration. Demand response with thermal storage optimization for wind integration was presented in the literature [25] with different algorithm for controllable sanitary hot water preparation. Another trade off between energy storage and transmission upgrade for optimal design with economic goal function might be seen in Ref. [27].
A study [29] on the power network in Serbia gave a wind penetration limit of $1 \mathrm{GW}$. According to another studies [30,31], CEEP can be significantly reduced if a revitalization of a thermal power plant (TPP) is made in order to reduce the technical minimum. A CEEP reduction can be also achieved by cycling in a TPP, which can be achieved by part load and two-shift operations [22]. Such operating conditions for thermal power units may result in an increase in costs. These costs arise from increased expenditures for maintenance and capital investment, forced outage effects, cost of forced outage time, replacement energy and capacity, cost of the increased unit heat rate [20], long-term efficiency and efficiency at low/variable loads, cost of start-up fuels, auxiliary power, chemicals and additional manpower required for unit start-up, long-term generation capacity costs also increase due to a shorter unit life [23]. According to Ref. [22], twoshift hot starts (for less than 8-h shutdowns) may be shortened to 40 min, giving good flexibility of the TPP needed for moderation.

Specific moderation costs from studies for wind integration under $15 \%$ of the total electricity production within the island mode for twelve countries range from 0.25 to $4 € / M W h$ of wind integrated $[8,12,18,32,33]$. These costs are additional costs for moderation of the system and they are higher when the share of wind-generated energy in the total energy generated increases, for higher wind projection mismatch and for the countries lacking storage plants.

They consist of capacity costs and operation costs due to wind power integration. Capacity costs are lost opportunity costs from not bidding on the spot energy market. These capacities are available from conventional power plants existing in a system and are based on additional reserves for the case that wind production deviates from that projected.

Within the connected island mode, competitive moderation costs vary with the system load and spot prices for energy [10]. When energy for balancing is not available from the power plants existing in a system, then the energy has to be purchased on the spot energy market. Operation costs are costs to supply energy and they are higher than capacity costs. Consisting of short-term marginal costs, cost increases due to part load and opportunity costs lost from bidding, operation costs might be between $27 € /$ MWh of balanced power supplied from coal power plants and $50 € /$ MWh from gas turbine plants [18]. These operational costs increase according to the generation cost supply curve of the available units on the spot market.

Cost savings can be realized by including variability as early as possible in the planning process to determine the optimal share of energy imbalance moderators $[19,34,35]$. There is no optimal design for all criteria, but there is an optimal solution according to certain criteria. Optimizations of different goals and under different constraints are shown in many articles. Minimization of the weighted costs [28] in the multi-area connected market model and operational costs [36] in the case of wind-thermal coordination with different types of constraints are examples of economic optimization criteria. Moderation requirements in the introduction phase of wind penetration are satisfied with increased consumer load flexibility, while in the large - scale integration phase, a synergetic approach for the heat and electricity sectors by using smart energy systems is needed [24]. Economic criteria are used in many articles [4,19,37-39] and more criteria have been added, thereby compromising the objective function with technical, environmental $[40,41]$, social and regulatory goals [16,42-44].

In this study, the amount of energy imbalance on a yearly base due to wind integration into the Serbian energy system has been calculated using EnergyPLAN. The EnergyPLAN tool is explained in Section 2. Then, the reference scenario for Serbia in the year 2009 is created in Section 3.1. Moderation costs are calculated for two scenarios: the island mode in Section 3.2 with the results given in Section 4.1 and in the connected island mode in Section 3.3 with the results given in Section 4.2. Two moderation strategies in the island 
mode are suggested in Section 3.4, with the results given in Section 4.3. The first strategy is reducing technical minima in thermal power units to exploit the effects of cycling further, which was proven before $[30,31]$ since investment in advanced process control in TPP promises to be lower compared to other moderation options. Another moderation strategy is demand response [45], especially flexible demand of electric heating [46,47], electric sanitary hot water preparation [25] and electric cooling [48] could be an interesting option for Serbia for two reasons: they are favourite end-use energy alternatives with high stock shares [49] and they may be cheaper than other moderation options [50,51]. With these strategies using EnergyPLAN, it was confirmed that the penetration level of wind into the existing Serbian energy system could be increased. Another study of a look-alike energy system [52] for increasing wind power penetration showed the best effects for sustainability for $10 \%$ share in final energy consumption.

It should be emphasized that the presented model does not take into account stochastics in wind turbine generation, heat rate loss in the TPP, start up/shut down costs and the load flows of the transmission capacity within the Serbian power system.

\section{Method}

The simulations for the Serbian national energy system were based on a user friendly, free, bottom up model based on the tool EnergyPLAN [53] with an hourly time-step. The EnergyPLAN tool may be used to assist in the design of national planning strategies by simulations of the electricity, heat and transport sectors and is suitable for the simulation of the scenarios for renewable energy penetrations [54]. With this model, it is possible to perform different control strategies based on operation costs and investment cost optimization. The model is based on the deterministic inputs of demands, renewable and fossil fuel generation, energy generation facilities, their efficiencies and different regulation strategies for import/export and minimization of energy imbalances. In this analysis, the national system was described by energy demands, generation capacities and efficiencies, types of energy sources, annual energy balances, fuel consumptions and $\mathrm{CO}_{2}$ emissions. Within EnergyPLAN, four criteria are used to quantify whether one energy system was better than another energy system:

1. CEEP (critical excess electricity production): is the yearly energy imbalance calculated on an hourly basis.

2. Annual costs: The annual generation costs required to supply the required energy demand, including $\mathrm{CO}_{2}$ costs.

3. $\mathrm{CO}_{2}$ : This is the amount of $\mathrm{CO}_{2}$ resulting from energy consumption and generation.

4. RES: The share of renewable energy in the total primary energy supply (TPES).

EnergyPLAN was utilized to analyze different levels of wind penetration. Energy imbalances for the island mode with a closed transmission system were calculated as CEEP values. The CEEP might be exported but the island mode in that scenario is violated. EnergyPLAN tool will perform TPP cycling (part load and two-shift operations) in the island mode to minimize fossil fuel usage.

\section{Case study: Serbian energy system}

\subsection{Reference scenario for Serbia}

The Serbian reference scenario for the year 2009 island mode was modelled using the closed system in EnergyPLAN. The electricity demand curve and yearly consumption were obtained from European Network of Transmission System Operators for Electricity
(ENTSO-E) data [55]. District heating (DH) and combined heat and power (CHP) data were obtained from Ref. [56]. Thermal power unit data were taken from Ref. [57] while the fuel data were from International Energy Agency (IEA) balances for 2009 [58] and the efficiencies were calculated from data found in Ref. [59]. The heat demand and load curve was calculated in Excel using the degreeday methodology and the temperature obtained from the METEONORM program for four cities in Serbia (Belgrade, Novi Sad, Niš and Čačak) [60]. The generation curves for run-off river hydro, storage hydro and pump storage electric power units were calculated from monthly balances obtained from Refs. [55], while the capacities were obtained from Ref. [57]. Division of the capacity between run-off river and storage hydro units was performed based on the sum of their annual energy generation obtained from Ref. [55]. Fuel quantities and their distribution for the individual household, industry and the transport sector were obtained from Ref. [58], except for the biomass used in the individual heating sector which was from the year 2010 [61]. The technical minimum for TPPS calculated as an equivalent unit is 70\% [59]. These TPP units were commissioned between 1956 and 1991 [59] for a base load operation and with low flexibility. This high value illustrates technological constraints for production in one unit and it is equivalent technical minimum when all TPPS are available on the grid. Due to planned maintenance lasting 48-64 days [59] and forced outage rate of $10.7-23.5 \%$ [59] for the main generating units (units above $190 \mathrm{MW}$ of rated power), this percentage is lower in operation. Assuming that at least one generator is not available, the technical minimum is $55-65 \%$ percent, assumed to be $60 \%$ in the reference scenario. Due to the low quality lignite at the current technology level in these units, operation under $70 \%$ of the rated power is possible only with the addition of liquid fuels of higher calorific value. With this procedure, it is possible to reduce the technical minimum down to $50 \%$ of the rated power. Bearing in mind the constrained availability of generators in operation, $40 \%$ of the technical minimum is assumed for scenario with the addition of liquid fuel. Costs of fuel $[59,62]$, investment, fixed operation and maintenance costs $[63,64]$ for the power technologies were based on the year 2008. The fuel $\mathrm{CO}_{2}$ content and price used are given in Table 1.

\subsection{Island mode scenario of wind penetration}

Technical optimization was performed for the island mode. In this mode, no interconnection grid moderation was used to emphasize the critical situations due to variability of wind generation. The yearly wind generation curve was calculated for turbines Vestas V90 2 MW, Ecotecnia 3.0 Class II and Re Power 5 MW based on a historical wind speed curve from a location in Vojvodina measured at $10 \mathrm{~m}$ and projected to heights of $80 \mathrm{~m}$ and $100 \mathrm{~m}$, with a wind shear coefficient of 0.25 [65]. Subsequently, the unit generation was multiplied to the installed capacity by using linear extrapolation. The dispatch was optimized using hydro storage, thermal power units and CHP units for balancing the electricity and heat demand, while no wind curtailments were allowed. Run-off river hydro units had priority in electricity generation. Hydro storage units were used for the best utilization of all water input and to avoid CEEP. Pumped hydro units were used in the same

Table 1

Fuel prices and $\mathrm{CO}_{2}$ content in fuels $[59,62]$.

\begin{tabular}{|c|c|c|c|c|c|c|c|}
\hline & Coal & Fuel oil & Diesel & Petrol & N. gas & LPG & Biomass \\
\hline Fuel prices $[€ / G J]$ & 1.45 & 10.76 & 14.8 & 16.2 & 4.87 & 11.27 & 2.66 \\
\hline $\begin{array}{l}\mathrm{CO}_{2} \text { content in fuel } \\
{[\mathrm{kg} / \mathrm{GJ}]}\end{array}$ & 100 & 74 & 74 & 74 & 56.7 & 66.7 & - \\
\hline
\end{tabular}


manner as hydro storage units with pumping to avoid CEEP. The turbine mode of operation was used in the pumped hydro units ensuring that the storage level was the same at the beginning and at the end of the year. The TPPS were used if demand was still higher than the supply or generation was requested for moderation. The thermal units were modelled at the same heat rates and efficiencies for all generation levels.

Eleven levels of wind penetrations up to the maximal envisaged capacity were simulated observing the four previously mentioned criteria (see Section 2). During operation, the share of units capable for supplying ancillary services is not less than $30 \%$. Variable sources were not allowed to provide ancillary services.

Additional system costs due to wind integration were calculated according to equation (1):

Cost $=C_{\text {GENERATION }}+C_{\text {MODERATION }}-C_{\text {GENERATION,REFERENCE }}$

$C_{\text {MODERATION }}=E_{\text {WIND }}{ }^{*} S C_{\text {MODERATION }}$

where:

$C_{\text {GENERATION }}$ are the annual costs required to supply the required energy demand $[\mathrm{M} € / \mathrm{a}]$,

$C_{\text {MODERATION }}=E_{\text {WIND }}{ }^{*} S C_{\text {MODERATION }}$ are the annual moderation costs $[\mathrm{M} € / \mathrm{a}]$,

$C_{\text {GENERATION, REFERENCE }}$ are the annual costs required to supply the reference scenario demand without wind integration $[\mathrm{M} € / \mathrm{a}]$, $E_{W I N D}$ is the annual wind energy generation [TWh/a],

$S C_{\text {MODERATION }}$ are the average specific moderation costs [M€l TWh],

\subsection{Connected island mode scenarios of wind penetration}

Additional system costs due to wind integration in connected island mode were calculated for different levels of wind penetration using EnergyPLAN.

This scenario is based on the previous, with the market and the technical optimization criterion applied. With a transmission capacity of $3600 \mathrm{MW}$ [66], with 8 (eight) surrounding countries, energy imbalances can be moderated well in regional interconnection. Since no regional market existed in 2009, a German spot market price from European energy exchange (EEX) with an average price $40-50 € / M W h$ was used to simulate the same eleven levels of wind penetration of up to $2500 \mathrm{MW}$. Assuming that the TSO is only in possession of real-time hourly generation and consumption data and that variable energy generation can be predicted accurately, marginal cost of cheapest available generator in interconnection (with addition of energy transport costs) is a signal for unit market commitment.

\subsection{Suggested moderation strategies}

For an illustration of increased flexibility strategy in TPPS, three scenarios were chosen:

- Reference scenario: technical minimum is $60 \%$ of the rated power, illustrating the technical availability of the units and current technology level,
- Additional fuel scenario: technical minimum is $40 \%$ of the rated power, illustrating the technical availability of the units and the addition of liquid fuel of higher calorific value to compensate the low quality lignite,

- Modern TPP: technical minimum is $20 \%$ of the rated power, as in a modern TPP in Europe with enhanced flexibility, illustrating the best available technology upgrade of a TPP.

Theoretical yearly energy potential in a flexible load for a smart energy system demand response is the following: hot water preparation (4.8 TWh), electric space heating (2.9 TWh), refrigerators (0.9 TWh), freezers $(0.9 \mathrm{TWh})$ and air conditioning $(0.8 \mathrm{TWh})$ [49]. Not all of this potential is flexible but it is stated as the upper bound. The technical, economic and realizable potentials are lower due to daily and seasonal patterns of use, costs and the acceptance of demand response technologies. In this paper, not less than $2500 \mathrm{MW}$ flexibility in $1 \mathrm{~h}$ and that all sanitary hot water preparations were flexible for one day were assumed. This flexible capacity was used assuming that further utilization of the DR potential capacity in sanitary hot water preparation would not have a CEEP lowering effect for the $2500 \mathrm{MW}$ of wind integrated. It was assumed that thermal storage in the buildings was sufficient for keeping sanitary hot water preparation and consumption flexible during one day. The investment cost for making this capacity flexible is $200-400$ US\$/KW and $10-300$ US\$/KWh of served energy. These costs are not part of the cost model.

\section{Results of wind integration}

Reference data obtained from ENTSO-E [55] and from IEA [58] and the reference scenario for Serbia in EnergyPLAN within the island mode are in very good agreement, as can be seen in Table 2. Without wind generation, the electricity export was around 0.26 TWh during the spring and summer, while import was around 0.85 TWh during the autumn and winter. The maximal hourly imbalance was $1828 \mathrm{MW}$ in the island mode scenario.

\subsection{Island mode technical optimization scenario}

Based on the methodology presented in Section 2, the resulting CEEP was calculated for different levels of wind penetration. These results together with an illustration of $10 \%$ of the total wind generation are presented in Fig. 1a to give a snapshot of the performance of the energy system under wind integration. The criteria of planner, previously used in Refs. [30], state that an energy system with a CEEP below $5-10 \%$ of the total variable generation is acceptable on economic grounds. The decrease in $\mathrm{CO}_{2}$ emission and the percentage $\mathrm{CO}_{2}$ reduction for different levels of installed wind power are show in Fig. 1b.

For the above wind penetration levels, the high values of CEEP (above $10 \%$ of the total wind generation) show that the whole envisaged capacity of wind power cannot be moderated in the existing Serbian energy system without external moderators or wind curtailment. The maximal calculated hourly value for CEEP of 3567 MW could be completely moderated within the regional market dispatch, which is shown on the CEEP duration curve shown in Fig. 2. The coloured area refers to CEEP in MWh. The

Table 2

Comparison of the reference data $[55,58]$ for 2009 and reference scenario in EnergyPLAN.

\begin{tabular}{|c|c|c|c|c|c|c|}
\hline & TPES & River hydro & Storage hydro & Pump hydro storage & Thermal & $\mathrm{CO}_{2}$ emissions \\
\hline & [Mtoe] & [TWh] & & & & {$\left[\mathrm{Mt} \mathrm{CO} \mathrm{CO}_{2}\right]$} \\
\hline Reference data & 14.45 & 9.576 & 0.914 & $0.603 / 0.915$ & 30 & 46.26 \\
\hline EnergyPLAN & 14.37 & 9.57 & 0.91 & $0.61 / 0.8$ & 26.8 & 46.033 \\
\hline
\end{tabular}



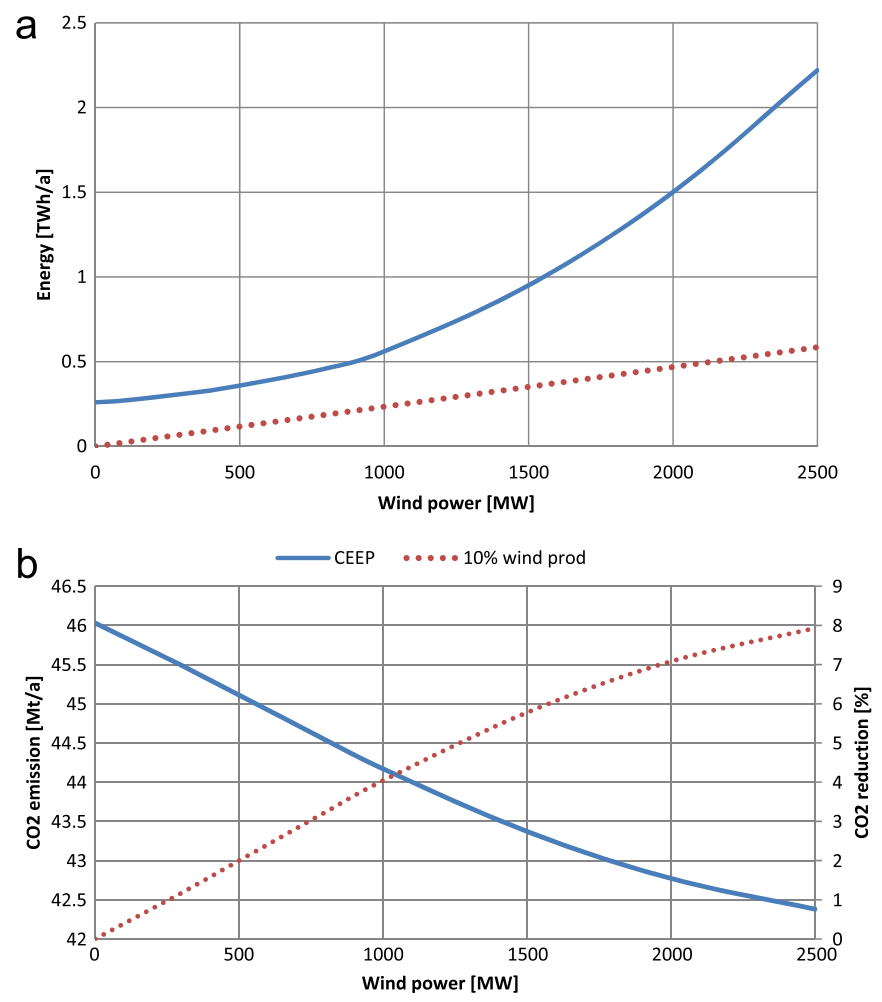

CO2-emission $\quad \cdots . .$. CO2-reduction

Fig. 1. Different levels of wind penetrations in island mode technical optimization: a) CEEP, and $10 \%$ of wind generation. b) Emissions of $\mathrm{CO}_{2}$, and possible emission reductions up to $8 \%$.

upper and lower limits for moderation costs, which increase linearly with the amount of integrated wind, are 1.4-23.4 M€ for the case of maximal wind penetration (see Eq. (2) in Section 3.2.). The total generation costs also increase from $7010 \mathrm{M} €$ to $7271 \mathrm{M} €$ in the case of maximal wind penetration.

The resulting additional costs of wind integration including generation and moderation (calculated for specific moderation costs of $2 €(\mathrm{MWh}$ ), and benefits in the improvement in the share of renewable energy sources and $\mathrm{CO}_{2}$ reduction are shown in Fig. 3 . The increase in costs due to wind integration is up to $3.9 \%$ in comparison to the reference scenario. An improvement in the share of renewable energy sources (including biomass) in the TPES is possible up to $4 \%$. The reference scenario with around $46 \mathrm{Mt} \mathrm{CO}_{2}$

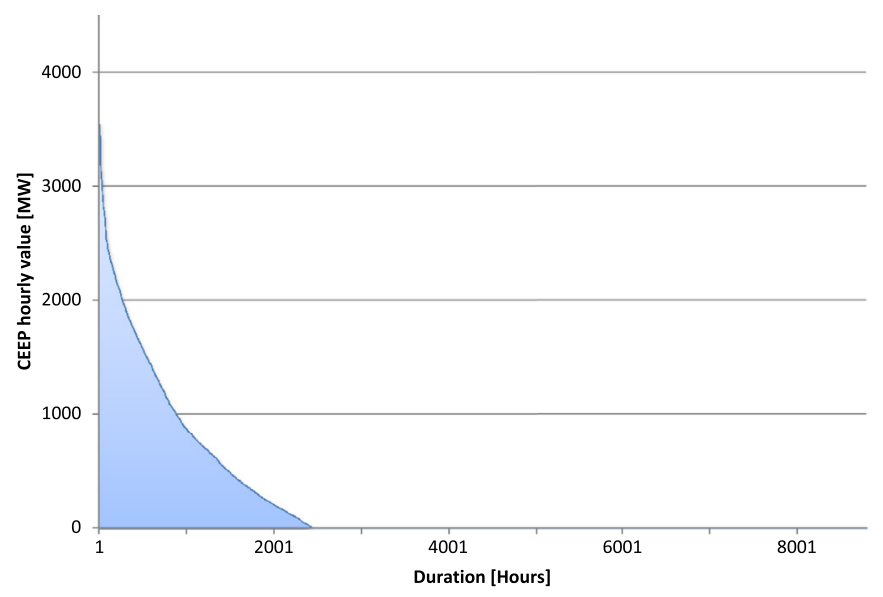

Fig. 2. CEEP duration curve.

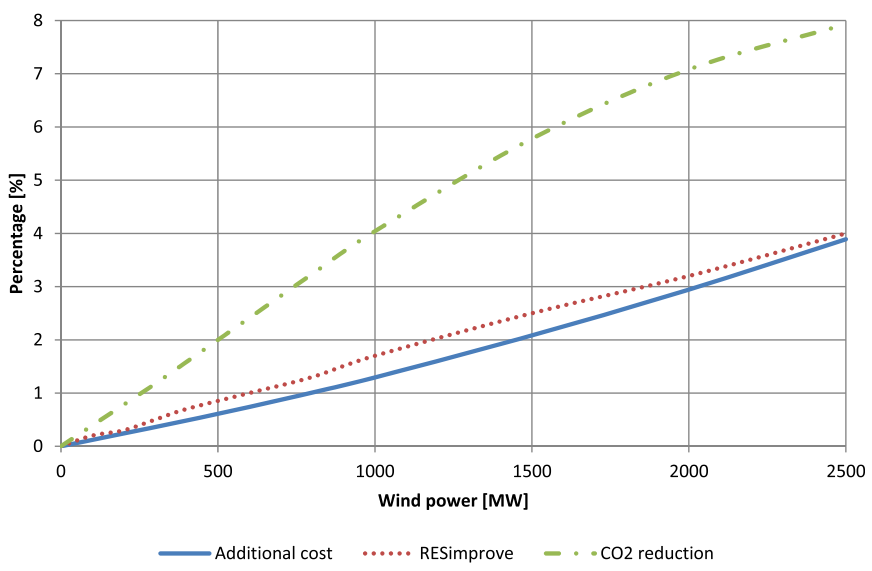

Fig. 3. Results of different levels of wind penetration in comparison to the reference scenario.

may be improved by almost $8 \%$ percent $\mathrm{CO}_{2}$ reduction when $2500 \mathrm{MW}$ of wind is integrated. These benefits and costs might be goals that should be satisfied with minimal deviations. The suggested goal for costs should not to be violated, while for renewable energy sources, the exceeded values of the share in the TPES and $\mathrm{CO}_{2}$ reduction are desirable.

Total system costs rise with more investment in wind power at reasonable prices of $\mathrm{CO}_{2}$ (in this paper $10 € / \mathrm{tCO}_{2}$ is assumed). From Fig. 3 , it is clear that there are no pronounced extremes in the benefits and costs functions.

\subsection{Connected island mode technical and market optimization scenario}

The trading of energy imbalances from wind integration at the spot market for an average price of $50 € / \mathrm{MWh}$ shows positive economic effects in the connected island mode and results in earnings in the market optimization scenario and after $300 \mathrm{MW}$ of wind, or more, is integrated in the technical optimization scenario (see Fig. 4).

A comparison of the moderation costs for the connected island mode technical and market optimization scenarios of wind integration of up to $2500 \mathrm{MW}$ with an average market price of $50 € /$ MWh is presented in Table 3.

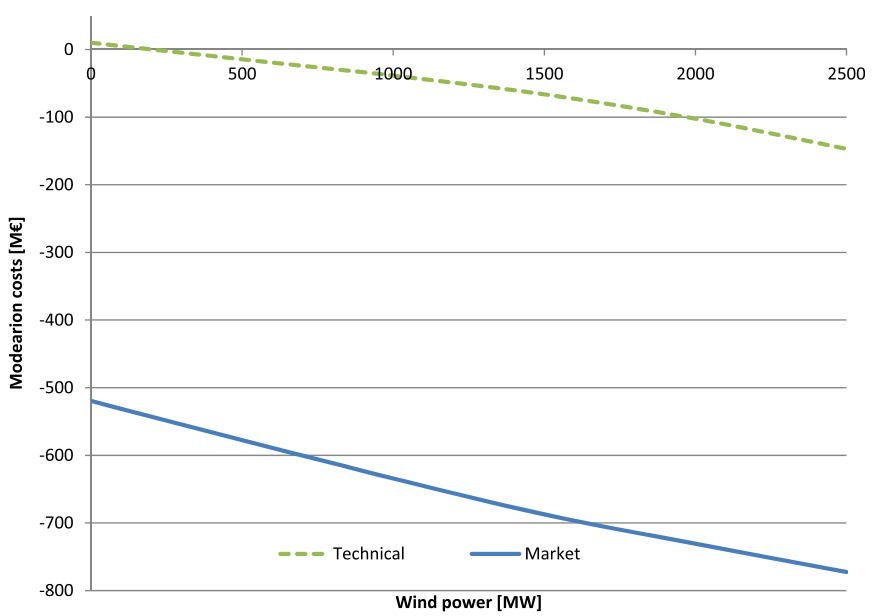

Fig. 4. Moderation costs for average market price of $50 € / \mathrm{MWh}$ in connected island mode market and technical optimization scenario. 
Table 3

Comparison of optimization scenarios of $2500 \mathrm{MW}$ wind integration in connected island mode for average market price of $50 € / \mathrm{MWh}$.

\begin{tabular}{lllllll}
\hline $\begin{array}{l}\text { Optimization } \\
\text { scenario }\end{array}$ & $\begin{array}{l}\text { Average price } \\
{[€ / \mathrm{MWh}]}\end{array}$ & $\begin{array}{l}\text { Cost } \\
{[\mathrm{M} € / \mathrm{a}]}\end{array}$ & $\begin{array}{l}\mathrm{CO}_{2} \\
{[\mathrm{Mt} / \mathrm{a}]}\end{array}$ & $\begin{array}{l}\mathrm{CO}_{2} \mathrm{corr} \\
{[\mathrm{Mt} / \mathrm{a}]}\end{array}$ & $\begin{array}{l}\text { RES share } \\
{[\% \text { of TPES] }}\end{array}$ & $\begin{array}{l}\text { TPES } \\
{[\mathrm{TWh} / \mathrm{a}]}\end{array}$ \\
\hline $\begin{array}{l}\text { Technical } \\
\text { Market }\end{array}$ & 50 & 7153 & 43.807 & 40.444 & 17.2 & 166.78 \\
& & 6935 & 58.246 & 41.026 & 13.9 & 206.95 \\
\hline
\end{tabular}

Although this price (average market price of $50 € / \mathrm{MWh}$ ) is higher than the marginal cost of an energy unit produced in an average Serbian TPP ( $35 € / M W h)$, market earnings resulted as the TPPS were in operation with more generation hours. Earnings together with a slight increase in generation costs from lignite result in lower total costs compared with island mode scenario and reference scenario. These earnings are higher in the market optimization scenario than in the technical optimization scenario and they increase with more wind integrated. The total $\mathrm{CO}_{2}$ emissions from the TPES are higher in market optimization scenario, while the share of renewable energy sources in the TPES is lower because more energy is produced from fossil fuels. Although, the export corrected $\mathrm{CO}_{2}$ emissions are reduced in both the connected island mode scenarios than in the island mode reference scenario, the connected island mode scenarios are unfavourable because the total amounts of $\mathrm{CO}_{2}$ are increased.

\subsection{Suggested moderation strategies for the Serbian energy system}

The results given in the previous subsection show an increase in the generation and moderation costs with higher levels of wind penetrations in the island mode scenario. In the open market scenario, the connected island mode, it was shown that exporting energy imbalances results in earnings (see Fig. 4) but the associated increased fuel consumption and total emissions (Table 3.), in comparison to reference scenario, make it difficult to meet EU2020 goals. Trading energy imbalances and wind projections might not be as perfect as assumed. In real situations, wind generation might demand unexpected moderation that may result in an increase in moderation costs according to spot market prices, making this moderation scenario unfavourable.

In this paper, two least-cost strategies are suggested, i.e. increased TPP generation flexibility and sanitary hot water preparation flexibility increased to one day (see Section 3.4).

The results of a quantification of the effects resulting from these moderation strategies for the energy system with $2500 \mathrm{MW}$ of wind power installed, in the island mode, are given in Table 4.

From Table 4, it is obvious that the total costs of the system with wind integration are reduced due to fossil fuel reductions, which results in reduction of emission by $8 \%$. After employing a demand response strategy, the emissions could be further reduced by $2 \%$ and the share of RES in the TPES increased by $0.4 \%$. Furthermore, an additional $6 \%$ emissions reduction and $0.8 \%$ increase in the share of RES in the TPES may be achieved by the application of a technical minima reduction strategy. The CEEP for the three scenarios of

Table 4

Effects of moderation strategies for $2500 \mathrm{MW}$ installed wind power in island mode.

\begin{tabular}{llllll}
\hline & $\begin{array}{l}\text { TPP min } \\
{[\mathrm{MW}]}\end{array}$ & $\begin{array}{l}\text { Cost } \\
{[\mathrm{M} € / \mathrm{a}]}\end{array}$ & $\begin{array}{l}\mathrm{CO}_{2} \\
{[\mathrm{Mt} / \mathrm{a}]}\end{array}$ & $\begin{array}{l}\text { CEEP } \\
{[\mathrm{TWh} / \mathrm{a}]}\end{array}$ & $\begin{array}{l}\text { RES share } \\
{[\% \text { of TPES] }}\end{array}$ \\
\hline 60\% Ref. TPP min & 2361 & 7275 & 42.383 & 2.22 & 17.7 \\
Demand response & 2361 & 7169 & 40.525 & 1.59 & 18.1 \\
$40 \%$ TPP min & 1574 & 7218 & 40.334 & 0.74 & 18.3 \\
20\% TPP min & 787 & 7205 & 39.845 & 0.44 & 18.5 \\
\hline
\end{tabular}

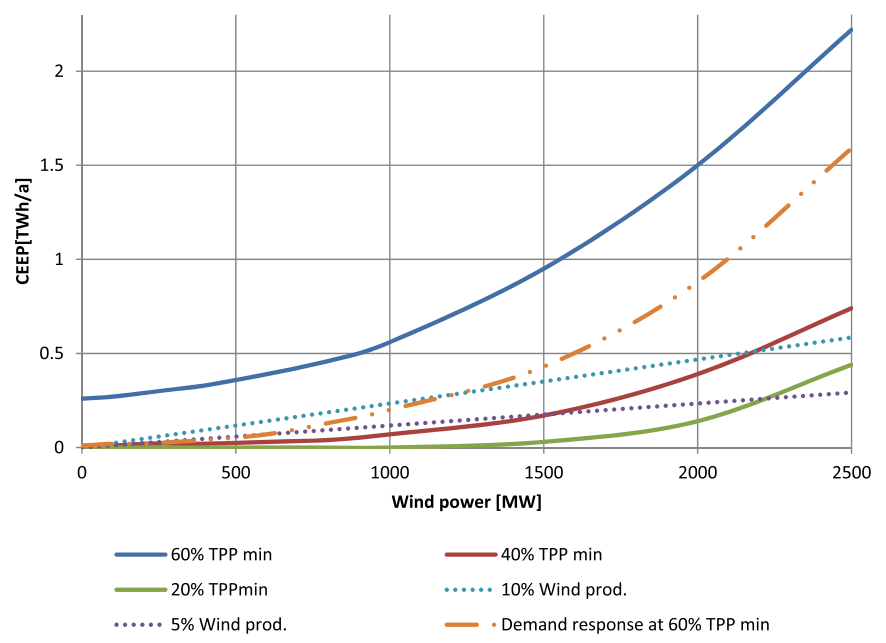

Fig. 5. Comparison of suggested moderation strategies for CEEP lowering.

technical minima reduction in the TPPS and the demand response strategy is shown in Fig. 5. The boundaries of the criteria from the experience of planners that CEEP has to be kept under a desired percent of the total wind generation are illustrated with dotted lines.

With a technical minima reduction from $60 \%$ in the reference scenario to $40 \%$, it is possible to integrate $1500 \mathrm{MW}$ of wind power with a CEEP below 5\% of wind generation, and $1750 \mathrm{MW}$ of wind may be integrated with a CEEP as in the reference scenario. With the technical minimum at $20 \%$ of the maximal load, another $700 \mathrm{MW}$ of wind power could be integrated, which makes a total of 2200 MW of wind power that could be integrated with a CEEP under $5 \%$ and $2500 \mathrm{MW}$ with a CEEP under $10 \%$ of the total wind generation. The increased consumer load flexibility with demand response in sanitary hot water lowers the CEEP by $0.3-0.61 \mathrm{TWh} / \mathrm{a}$, in comparison to the reference scenario with, the technical minimum at $60 \%$. The demand response strategy opens space for the integration of $500 \mathrm{MW}$ with CEEP under 5\% and $1200 \mathrm{MW}$ of wind with the reference CEEP or with CEEP under $10 \%$.

\section{Conclusions}

Bearing in mind the good availability of moderation options in the existing Serbian energy system, it has been shown that it is possible to integrate more wind than was previously envisaged with the feed-in tariff and available studies.

The suggested moderation strategies in the Serbian energy system in the island mode with installation of significant wind power reduce the CEEP, increase the share of renewable energy in the TPES and save both fuel and emissions.

With advanced flexibility as seen in modern thermal power plants, the envisaged wind capacity could be integrated in the island mode. Fully increased consumer load flexibility of sanitary hot water preparation yearly energy demand could moderate the whole wind generation eligible within the feed-in tariff.

A study to determine the optimal share of RES penetration into the Serbian energy system should be realized in future comparing all moderation strategies.

\section{Acknowledgements}

This work was financed under contract number 42009 of the Serbian Ministry of Education, Science and Technological Development. A preliminary version of this work was presented at the 
7th conference on Sustainable Development of Energy, Water and Environmental Systems, organized by Faculty of Mechanical Engineering and Naval Architecture Zagreb in Ohrid in 2012.

\section{References}

[1] Lund H, Mathiesen BV. The role of carbon capture and storage in a future sustainable energy system. Energy 2012;44(1):469-76.

[2] Kovacević A. Fossil fuel subsidies in the Western Balkans. Available at: www. undp.hr/upload/file/277/138767/FILENAME/Fossil_Fuel_Subsidies_F.pdf; 2011 [accessed 30.01.13].

[3] Komor P, Bazilian M. Renewable energy policy goals, programs, and technologies. Energy Policy 2005;33(14):1873-81.

[4] Rajaković N, Batas Bjelić I. Optimal renewable sources share in final energy consumption of Republic Serbia [in Serbian]. In: First renewable energy sources conference. Belgrade; 2011. p. 1-6.

[5] Uredba o merama podsticaja za povlašćene proizvođače električne energije [in Serbian]. 8/2013 Official Gazette of the Republic of Serbia. Belgrade; 2013.

6] The energy law. 57/11: Official Gazette of the Republic of Serbia. Available at: www.aers.rs/FILES/Zakoni/Eng/Zakon\%20o\%20energetici_57-11.pdf; 2011 [accessed 30.01.13].

[7] Đurišić Ž, Bubnjević M, Mikičić D, Rajaković N. Wind atlas of Vojvodina, Serbia. EWEC2007. Available at: www.ewec2007proceedings.info/allfiles2/249_ Ewec2007fullpaper.pdf [accessed 30.01.13].

[8] Johnsson F, Alliance for Global Sustainability, Pathways to Sustainable European Energy Systems. European energy pathways: pathways to sustainable European energy systems. Göteborg: Alliance for Global Sustainability (AGS); 2011.

[9] Kezunović M, Vittal V, Meliopoulos S, Mount T. The big picture: smart research for large-scale integrated smart grid solutions. IEEE Power and Energy Magazine 2012;10(4):22-34.

[10] Hirst E, Kirby B. Unbundling generation and transmission services for competitive electricity markets: examining ancillary services. Oak Ridge, Tennessee 378311-92. Available at: www.ipu.msu.edu/library/pdfs/nrri/ Hirst-Kirby-Unbundling-Generation-98-05-Jan-98.pdf; 1998 [accessed 30.01.13].

[11] Garcia MP, Kirschen DS. Forecasting system imbalance volumes in competitive electricity markets. In: Power systems conference and ...; 2004;21(1): 240-8.

[12] De Vos K, Driesen J, Belmans R. Assessment of imbalance settlement exemptions for offshore wind power generation in Belgium. Energy Policy 2011;39(3):1486-94.

[13] Sortomme E, Irani RR, Nguyen HV, El-Sharkawi MA. Estimating energy imbalance due to integration of wind power. In: Conference power and energy society general meeting. IEEE; 2010. p. 1-6.

[14] Lund H, Münster E. Management of surplus electricity-production from a fluctuating renewable-energy source. Applied Energy 2003;76(1-3):65-74.

[15] Mike D, Bob M, Baillie A. Transitioning from traditional to renewable infrastructure. Available at: www.aegislink.com/presentations/phc_2010/pdfs/ Transitioning_to_Renewable.pdf; 2010 [accessed 30.01.13].

[16] De Jonghe C, Hobbs BF, Belmans R. Optimal generation mix with short-term demand response and wind penetration. IEEE Transactions on Power Systems 2012;27(2):830-9.

[17] Østergaard PA. Ancillary services and the integration of substantial quantities of wind power. Applied Energy 2006;83(5):451-63.

[18] Klobasa M, Obersteiner C, Ragwitz M, Auer H. Strategies for an efficient integration of wind power considering demand response. Vienna: Energy Economics Group- Vienna University of Technology; 2007.

[19] De Jonghe C, Hobbs BF, Belmans R. Integrating short-term demand response into long-term investment planning. Faculty of Economics, University of Cambridge; 2011.

[20] Troy N, Denny E, O'Malley M. Base-load cycling on a system with significant wind penetration. IEEE Transactions on Power Systems 2010;25(2):1088-97.

[21] Göransson L, Johnsson F. Large scale integration of wind power: moderating thermal power plant cycling. Wind Energy 2011;14(1):91-105.

[22] Gostling J. Two shifting of power plant: damage to power plant due to cycling - a brief overview. OMMI 2002;1(1)

[23] Lefton S, Besuner P. The cost of cycling coal Fired power plants. Coal Power Magazine Winter 2006:16-20.

[24] Lund H, Andersen AN, Østergaard PA, Mathiesen BV, Connolly D. From electricity smart grids to smart energy systems - a market operation based approach and understanding. Energy 2012;42(1):96-102.

[25] Fitzgerald N, Foley AM, McKeogh E. Integrating wind power using intelligent electric water heating. Energy 2012;48(1):135-43.

[26] Bove R, Bucher M, Ferretti F. Integrating large shares of wind energy in macroeconomical cost-effective way. Energy 2012;43(1):438-47.

[27] Steinke F, Wolfrum P, Hoffmann C. Grid vs. storage in a $100 \%$ renewable Europe. Renewable Energy 2013;50(0):826-32.

[28] Lindgren E, Söder L. Minimizing regulation costs in multi-area systems with uncertain wind power forecasts. Wind Energy 2008;11(1):97-108.

[29] Serbia: power network analysis for wind power integration. EMS. Available at: www.ems.rs/stranice/novosti/press/EMS_presentation.pdf; 2011 [accessed 30.01.13].
[30] Ćosić B, Markovska N, Taseska V, Krajačić G, Duić N. Improving the RES absorption capacity of the Macedonian energy system. In: 24th international conference, on efficiency, cost, optimization, simulation and environmental impact of energy systems; 2011. p. 2556-64. Novi Sad, Serbia.

[31] Hong L, Lund H, Möller B. The importance of flexible power plant operation for Jiangsu's wind integration. Energy 2012;41(1):499-507.

[32] Helander A, Holttinen H, Paatero J. Impact of wind power on the power system imbalances in Finland. IET Renewable Power Generation 2010;4(1): 75-84.

[33] Holttinen $H$, Lemström B, Meibom P, Bindner $H$, Hulle OA, van Ensslin F, et al. Design and operation of power systems with large amounts of wind power. Available at: www.ieawind.org/AnnexXXV/Publications/W82.pdf; 2007 [accessed 30.01.13].

[34] Shortt A, Kiviluoma J, O’Malley M. Accommodating variability in generation planning. IEEE Transactions on Power Systems 2012:1-12.

[35] Xie L, Carvalho PMS, Ferreira LAFM, Liu J, Krogh BH, Popli N, et al. Wind integration in power systems: operational challenges and possible solutions. Proceedings of the IEEE 2011;99(1):214-32.

[36] Chen C-L, Lee T-Y, Jan R-M. Optimal wind-thermal coordination dispatch in isolated power systems with large integration of wind capacity. Energy Conversion and Management 2006;47(18-19):3456-72.

[37] Hobbs BF. Optimization methods for electric utility resource planning. European Journal of Operational Research 1995;83(1):1-20.

[38] Østergaard PA. Reviewing optimisation criteria for energy systems analyses of renewable energy integration. Energy 2009;34(9):1236-45.

[39] Milan C, Bojesen C, Nielsen MP. A cost optimization model for $100 \%$ renewable residential energy supply systems. Energy 2012;48(1):118-27.

[40] Petrović R, Kralj B. Economic and environmental power dispatch. European Journal of Operational Research 1993;64(1):2-11.

[41] Mathiesen BV, Østergaard PA, Connolly D, Pillay JR, Felby C, Meyer NI, et al. Coherent energy and environmental system analysis 2011. Aalborg $\emptyset$.

[42] Shrestha RM, Marpaung COP. Supply- and demand-side effects of power sector planning with $\mathrm{CO}_{2}$ mitigation constraints in a developing country. Energy 2002;27(3):271-86.

[43] Hobbs BF, Centolella P. Environmental policies and their effects on utility planning and operations. Energy 1995;20(4):255-71.

[44] Foley aM, Ó Gallachóir BP, Hur J, Baldick R, McKeogh EJ. A strategic review of electricity systems models. Energy 2010;35(12):4522-30.

[45] Pina A, Silva C, Ferrão P. The impact of demand side management strategies in the penetration of renewable electricity. Energy 2012;41(1):128-37.

[46] Hedegaard K, Mathiesen BV, Lund H, Heiselberg P. Wind power integration using individual heat pumps - analysis of different heat storage options. Energy 2012;47(1):284-93.

[47] Østergaard PA. Wind power integration in Aalborg Municipality using compression heat pumps and geothermal absorption heat pumps. Energy 2013;49(0):502-8.

[48] Ban M, Krajačić G, Grozdek M, Ćurko T, Duić N. The role of cool thermal energy storage (CTES) in the integration of renewable energy sources (RES) and peak load reduction. Energy 2012;48(1):108-17.

[49] Sensfuss F, Wietschel M, Eichhammer W. Preparation of a least cost investment plan for Serbia electricity sector 2005. Karlsruhe.

[50] Porter K, Mudd C, Fink S, Rogers J, Bird L, Schwartz L, et al. Meeting renewable energy targets in the west at least cost: the integration challenge. Denver, $\mathrm{CO}$ : Western Governors' Association; 2012.

[51] Energy GE. Western wind and solar integration study. No. NREL/SR-550 47434. Golden, CO: National Renewable Energy Laboratory (NREL); 2010.

[52] Dimitrijević Z, Salihbegović I. Sustainability assessment of increasing renewable energy sources penetration - JP Elektroprivreda B\&H case study. Energy 2012;47(1):205-12.

[53] Connolly D, Lund H, Mathiesen BV, Leahy M. A review of computer tools for analysing the integration of renewable energy into various energy systems. Applied Energy 2010;87(4):1059-82.

[54] Lund H. Large-scale integration of wind power into different energy systems. Energy 2005;30(13):2402-12.

[55] ENTSO-E - European network of transmission system operators for elec tricity. Available at: www.entsoe.eu/resources/data-portal/country-packages [accessed 30.01.13].

[56] Euroheat \& Power. Available at: www.euroheat.org/Statistics-69.aspx [accessed 30.01.13].

57] EPS. Technical report for the year 2009. Available at: www.eps.rs/Eng/ Tehnicki Izvestaji/EPS_Tehncki_Godisnjak2009_en_web.pdf [accessed 30.01.13]

[58] IEA - International Energy Agency. Available at: www.iea.org/stats/ balancetable.asp?COUNTRY CODE=RS [accessed 30.01.13]

[59] South East Europe Consultants. Study on the potential for climate change combating in power generation in the energy community. Available at: www. energy-community.org/pls/portal/docs/928177.PDF; 2011 [accessed 30.01.13].

[60] METEONORM. Global meteorological database for engineers, planners and education. Available at: www.meteonorm.com [accessed 30.01.13]

[61] Serbian energy balance. Ministry of Mining and Energy; 2012 [in Serbian].

[62] Ćosić B, Krajačić G, Duić N. 100\% Renewable energy system in the year 2050: the case of Macedonia. Energy 2012;48(1):80-7. 
[63] SETIS calculator. JRC, European Commission. Available at: odin.jrc.ec.europa. eu/SETIS/SETIS1.html\# [accessed 30.01.13].

[64] Danish Energy Agency. Technology data for energy plants. Danish Energy Agency. Available at: www.ens.dk/Documents/Netboghandel\%20-\%20publikationer/ 2010/Technology_data_for_energy_plants.pdf [accessed 30.01.13].
[65] Đurišić Ž, Mikulović J. A model for vertical wind speed data extrapolation for improving wind resource assessment using WAsP. Renewable Energy 2012;41:407-11.

[66] Indicative values for net transfer capacities (NTC) in Europe. Available at: www.entsoe.eu/resources/ntc-values/ntc-matrix/ [accessed 30.01.13]. 